\title{
Determining the optimum concentration of multiwalled carbon nanotubes as filtrate loss additive in field-applicable mud systems
}

\author{
Emeka E. Okoro ${ }^{1} \cdot$ Anita A. Zuokumor ${ }^{1} \cdot$ Ikechukwu S. Okafor $^{2} \cdot$ Kevin C. Igwilo $^{3} \cdot$ Kale B. Orodu $^{1}$
}

Received: 2 May 2019 / Accepted: 16 July 2019 / Published online: 22 July 2019

(c) The Author(s) 2019

\begin{abstract}
In a bid to combat fluid loss in muds where the effects of high downhole temperatures have pronounced effects on conventional fluid loss additives, several materials have over time been evaluated. One of such materials is the multiwalled carbon nanotubes (MWCNTs). Most studies in the literature limit the scope of their investigation to how the MWCNT affects mud rheology when added in minute concentrations $(0.01-1 \mathrm{ppb})$. In this study, however, the performance of high concentrations $(0.5-3 \mathrm{ppb})$ of multiwall carbon nanotubes as fluid loss control additives in field-applicable mud systems was put to the test. The essence was to establish an optimal concentration useful for field applications. The degree to which the introduction of varying concentrations of the MWCNT altered the muds capacity to control filter loss was the cardinal areas evaluated. The following are the major outcomes of the experimental study: The plastic viscosity, the yield point and the gel strengths showed a progressive increase as the concentration of the MWCNT in the mud increased for both the water- and oil-based muds. However, an optimum concentration of $2 \mathrm{ppb}$ was observed for the water-based mud. For the filter loss tests on the oil-based mud, the results indicate that low concentrations ( $0.5 \mathrm{ppb})$ of the MWCNT led to high filter loss volumes (15 ml), but an increase up to $2.5 \mathrm{ppb}$ reduced the margin of the filter loss volume by $52 \%(7 \mathrm{ml})$ from the initial value and a $50 \%$ decrease for the standard case. In the case of the water-based mud, equivalent amounts of MWCNT recorded less fluid loss than the standard. A moderately hard and firm cake was reported for all concentrations of the standard and MWCNT for the water- and oil-based muds; however, their cake thickness values were $2 \mathrm{~mm}$ and $1 \mathrm{~mm}$ for the water- and the oil-based muds, respectively.
\end{abstract}

Keywords Filter loss $\cdot$ Multiwalled carbon nanotubes $\cdot$ Oil-based mud $\cdot$ Water-based mud $\cdot$ Optimum concentration

\section{Introduction}

While a driller looks forward to drilling a well that brims with stability, resilience and integrity, he needs to ascertain the effectiveness of the mud he intends to use (Okoro et al. 2015). According to M-I Swaco (2006), an effective drilling fluid should enable a well to meet its desired objective of producing oil and gas at the lowest overall cost, while minimizing formation damage and other hole problems.

Emeka E. Okoro

emeka.okoro@covenantuniversity.edu.ng

1 Petroleum Engineering Department, Covenant University Ota, Ota, Nigeria

2 Petroleum Engineering Department, Nile University in Nigeria, Abuja, Nigeria

3 Petroleum Engineering Department, Federal University of Technology Owerri, Owerri, Nigeria
Filtration control is often considered the most important property of a drilling fluid, particularly during overbalance drilling of permeable formations (Okoro et al. 2018; Baker Hughes 2006). Filtration of drilling fluids occurs because of the pressure differential between the drilling mud and the surrounding wellbore. The pressure causes the filtrate to flow into the pores of the formation, leaving particles on the sides of the wellbore (Warren et al. 1993). Mud engineers are tasked with formulating drilling fluids that have good filtration properties. A properly formulated drilling fluid should form a thin filter cake on the wall of the drilled borehole and allow minimal filtrate loss into the surrounding formation (Agwu and Akpabio 2018). It is important to select the right control agents for fluid loss in order to reduce filtrate invasion into the formation and the associated issues. Clays that easily hydrate in water are added to the mud at the surface; these clay particles increase the mud viscosity and form a low-permeability filter cake on the borehole

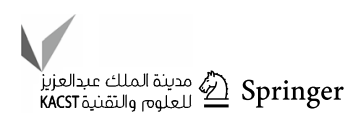


wall, leading to a reduction in fluid loss (Bourgoyne et al. 1991; Aftab et al. 2016; Allahvirdizadeh et al. 2016; Binqiang et al. 2018; Vipulanandan and Mohammed 2015; Azouz et al. 2016). Various natural and synthetic polymers such as starch, carboxymethyl cellulose, xanthan gum and polyacrylamide are used as control additives to reduce fluid loss and modify the rheological properties of drilling mud (Ahmad et al. 2017; Dias et al. 2015; Hamed and Belhadri 2009; Xuan et al. 2014; Ekeinde et al. 2018). Research has shown that these polymers are inefficient at high-pressure and high-temperature conditions (Igwe and Kinate 2015). Bourgoyne et al. (1991) reported that carboxymethyl cellulose (CMC) might be used in temperatures up to $300^{\circ} \mathrm{F}$ while starch begins to degrade above $200^{\circ} \mathrm{F}$. But, some recent studies have shown that nanoparticles (NP) exhibit better fluid loss control, shear thinning and extended temperature stability compared to conventional fluid loss additives (Dmitry et al. 2011; Sharma et al. 2012). Due to their extremely small size, NP has the ability to fill the smallest pores and pore throats and acts as a sealing agent in all lithology, which leads to improved fluid loss control (Oscar et al. 2014). The application of nanoparticles in formulating high-performance drilling fluids is a sustainable solution, which has the potential to overcome technical challenges encountered by the drilling industry (Abduo et al. 2016; Vryzas and Kelessidis 2017).

\section{Carbon nanotubes}

Carbon nanotubes (CNT) are notable examples of nanoparticles, which have successfully improved drilling mud properties (Ismail et al. 2014; Aftab et al. 2016; Shadfar et al. 2016). A CNT is a substance which has the same chemical composition as the carbon atom, coupled with a unique cylindrical physical structure (Wang et al. 2009). It has a combination of features like low density, nanoscale dimensions, very high surface area, high aspect ratio (length/ diameter) which set them apart from other materials (Mehra et al. 2014). CNTs exist in two forms, namely single-walled CNT and multiwalled CNT. Various investigators have reported the use of multiwalled carbon nanotubes in improving rheological characteristics of water-based mud (Ismail et al. 2016; Mostafa et al. 2016; Abduo et al. 2016; Shadfar et al. 2016) and oil-based mud (Mostafa et al. 2016). Ismail et al. (2014) studied the effects of different concentrations of MWCNT such as 0.001, 0.01, 0.1 and 1 ppb on waterbased drilling fluids and recorded a filtrate loss of $65 \%$ in the presence of $1 \mathrm{~g}$ of the additive. Ismail et al. (2016) investigated the effects of adding MWCNTs in wider concentration ranges of $0.001,0.002,0.01,0.02,0.1$ and $0.2 \mathrm{ppb}$ on the filtration, lubricity and rheological properties of water-based mud. They concluded that the MWCNT is a good choice for additives for water-based muds.
The objective of this study is to determine the effects of increased concentrations of MWCNT particles, up to $3 \mathrm{ppb}$, on the fluid loss behavior of aqueous and nonaqueous drilling fluid systems.

\section{Methodology}

Field standard water- and oil-based drilling muds were prepared in the laboratory as control, and each of the mud systems was reproduced with MWCNT in increasing concentrations of $0.5-3 \mathrm{ppb}$ for aqueous and nonaqueous mud systems. These mud systems were analyzed for their rheological properties using a viscometer, and a filtration test was conducted using API filter press for the water-based mud and HPHT filter press for the oil-based mud systems (API RP 13B-1). API static filter press is used for the water-based mud at ambient (room) temperature and 100 psi differential pressure, while HPHT filter press half-cell is used for oilbased mud system at $200 \mathrm{~F}$ and 200 psi differential pressure. The filter cakes developed during this process were analyzed and physically characterized. All the work carried out was in line with API-recommended practice of formulating and testing drilling fluids.

\section{Materials}

The materials used in the formulation of the mud samples are tabulated in Table 1. Samples of carbon nanotubes were received from the University of the Witwatersrand Johannesburg, South Africa, and other additives were provided by BLS Mud Service Company, Rivers State, Nigeria. The samples were collected in new quality packs, labeled properly and immediately transported to the laboratory for analysis.

Table 1 Mud additives and their functions

\begin{tabular}{ll}
\hline Additive & Function (s) \\
\hline $\begin{array}{l}\text { Barite } \\
\text { Soda ash }\end{array}$ & $\begin{array}{l}\text { Weighting agent } \\
\text { Calcium precipitant and } \mathrm{pH} \text { reducer in } \\
\text { cement-contaminated mud }\end{array}$ \\
Diesel oil/Water & $\begin{array}{l}\text { Base fluid } \\
\text { X-CIDE 102 }\end{array}$ \\
PAC R & Viscosifrol of viscosity and filtration \\
PAC L & Viscosifier and fluid loss control \\
Sodium hydroxide & pH control \\
NaCl & Control borehole stability \\
MWCNT & Rheology improvement and fluid loss control
\end{tabular}




\section{Sample preparation}

The BET analysis result of the MWCNT is as follows: surface area $-70.9234 \mathrm{~m}^{2} / \mathrm{g}$, pore volume $-0.213971 \mathrm{~cm}^{3} / \mathrm{g}$, pore size $-12.06771 \mathrm{~nm}$ and oxidation temperature $\sim 626^{\circ} \mathrm{C}$.

\section{Pre-treatment of MWCNT}

Owing to their hydrophobic nature, MWCNTs are not readily dispersed in water (see Fig. 8 under Appendix for MWCNT picture); hence, hydrophilic functional groups were introduced onto its surface by treating it with nitric acid (Wepasnick et al. 2011). The MWCNT is mixed with nitric solution in order to enhance their distribution by introducing a hydrophilic/functional part (polar characteristic) on the MWCNT surface. The process of modification

Table 2 Laboratory formulation for preparation of equivalent to 1 barrel of WBM

\begin{tabular}{lllll}
\hline Product name & Mixing order & $\begin{array}{l}\text { Mix- } \\
\text { ing time } \\
\text { (mins) }\end{array}$ & SG & $\begin{array}{l}\text { Product conc. } \\
\text { for 1 lab bbl } \\
(350 \mathrm{mls}) \\
\text { lbs }\end{array}$ \\
\hline Base fluid & 1 & 0 & 1 & 325.13 \\
Viscosifier & 2 & 2 & 1.5 & 1.50 \\
Fluid loss addi- & 3 & 1 & & - \\
$\quad$ tive & & & & \\
Alkalinity & 4 & 2 & 2.5 & 0.25 \\
Salt & 5 & - & 3.31 & 14.54 \\
Other & 6 & 1 & 2.13 & 0.25 \\
Others & 7 & 2 & 1.07 & 0.25 \\
Barite & 8 & 5 & 3.9 & 70.0 \\
\hline
\end{tabular}

adopted is called covalent surface modification which involves the incorporation of hydrophilic substitutions into the exterior MWCNT side walls. After this, the sample was diluted with deionized water, filtered and washed repeatedly. The cleaned MWCNTs were dried in order to remove the water.

\section{Preparation of WBM samples}

The water-based drilling fluid was prepared by dissolving $325.13 \mathrm{ml}$ of deionized water with $0.25 \mathrm{ml}$ caustic soda and $1.25 \mathrm{ml}$ fluid loss additives for $2 \mathrm{~min}$ (Table 2). After that, $70.0 \mathrm{ppb}$ of barite, $1.5 \mathrm{ppb}$ of PAC L, $14.54 \mathrm{ppb}$ of salt and $0.25 \mathrm{ppb}$ of X-Cide 102 were added and the resulting suspension was mixed using a Hamilton Multimixer.

\section{Preparation of OBM samples}

The oil-based drilling fluid was prepared by mixing $165.5 \mathrm{ml}$ of oil with $8.0 \mathrm{ppb}$ organophilic clay, $1.0 \mathrm{ppb}$ viscosifier and $7.0 \mathrm{ppb}$ lime (Table 3). The mixing took place for about 4 min using a multimixer of $15,000 \mathrm{rpm}$ load speed. Next, $6.0 \mathrm{ppb}$ of primary emulsifier was added and mixed for $2 \mathrm{~min}$, after which $68.9 \mathrm{ppb}$ of the aqueous phase and $30.3 \mathrm{ppb}$ brine were added and mixed for $5 \mathrm{~min}$. Finally, $129.4 \mathrm{ppb}$ of bridging agent and $0.5-3 \mathrm{ppb}$ of fluid loss control agent were added and mixed for another 5 and $6 \mathrm{~min}$, respectively, to obtain oil-based drilling fluid of specific gravity of 1.2 .
Table 3 Laboratory formulation for preparation of equivalent to one barrel of OBM

\begin{tabular}{|c|c|c|c|c|c|c|}
\hline \multicolumn{2}{|l|}{ Mud weight: $1.2 \mathrm{sg}$} & \multicolumn{3}{|c|}{ Oil/water ratio: $75 / 25$} & \multicolumn{2}{|c|}{$\begin{array}{l}\text { Product conc. } \\
\text { For } 1 \text { lab bbl } \\
(350 \mathrm{mls})\end{array}$} \\
\hline Product & S. G & Unit size & Mixing order & $\begin{array}{l}\text { Mixing time } \\
\text { (mins) }\end{array}$ & $\mathrm{ml}$ & bbl \\
\hline Base fluid & 0.805 & bbl & 1 & 4 & 205.6 & 0.6 \\
\hline Organophilic clay & 1.7 & $\mathrm{lb}$ & & & 4.7 & 0.0 \\
\hline Viscosity modifier & 0.95 & $\mathrm{lb}$ & & & 1.1 & 0.0 \\
\hline Lime (pH enhancer) & 2.3 & $\mathrm{~kg}$ & & & 3.0 & 0.0 \\
\hline Emulsifier & 0.9 & gal & 2 & 2 & 6.7 & 0.0 \\
\hline Aqueous phase & 1 & bbl & 3 & 5 & 68.9 & 0.2 \\
\hline Brine phase $\left(\mathrm{CaCl}_{2}\right)$ & 3.64 & $\mathrm{~kg}$ & & & 8.3 & 0.0 \\
\hline Rheology modifier & - & gal & & & 0.0 & 0.0 \\
\hline Barite & 4.2 & $\mathrm{~kg}$ & 4 & 5 & 0.0 & 0.0 \\
\hline Bridging agent & 2.7 & $\mathrm{~kg}$ & & & 47.9 & 0.1 \\
\hline \multirow[t]{2}{*}{ Fluid loss agent } & 1.05 & $\mathrm{lb}$ & 5 & 6 & 3.8 & 0.0 \\
\hline & & & & & 350.0 & 1.0 \\
\hline
\end{tabular}




\section{Results and discussion}

\section{Mud behavior}

Shear stress is the force required to sustain the shear rate. It is reported in standard oil field units as the pounds of force per hundred square feet $\left(\mathrm{lb} / 100 \mathrm{ft}^{2}\right)$ required to maintain the shear rate. The mud viscometer dial readings taken from the experiment are converted to a shear stress with $\mathrm{lb} / 100 \mathrm{ft}^{2}$ units by multiplying the reading by 1.0678 . The plot of shear rate and stress is called a rheogram, and it is used to identify the nature of fluid under consideration. The absence or presence of the yield point in the plot identifies the fluid as Newtonian or non-Newtonian fluid. The shape of the curves obtained in Fig. 1a and $\mathrm{b}$ indicates that both the water- and oil-based muds formulated with the MWCNT are non-Newtonian fluids. This is due to the existence of a yield point with a value greater than zero. It is also observed that the yield point for both mud systems was on a steady increase as the concentrations of the MWCNT were increased. With an increase in the MWCNT concentration, decrease in the values of flow index and increase in consistency index; indicates that the mud systems are in line with power-law equation.

\section{Effect of MWCNT on the rheological properties of the mud systems}

\section{Plastic viscosity}

Plastic viscosity (PV) of a mud in its simplest terms is the internal resistance of that mud to flow (Abduo et al. 2016). Plastic viscosity is a combination of the viscosities of the base fluid and solids that act as additives in the drilling mud
Fig. 1 a Shear stress against shear rate at different concentrations of MWCNT for OBM. b Shear stress against shear rate at different concentrations of MWCNT for WBM

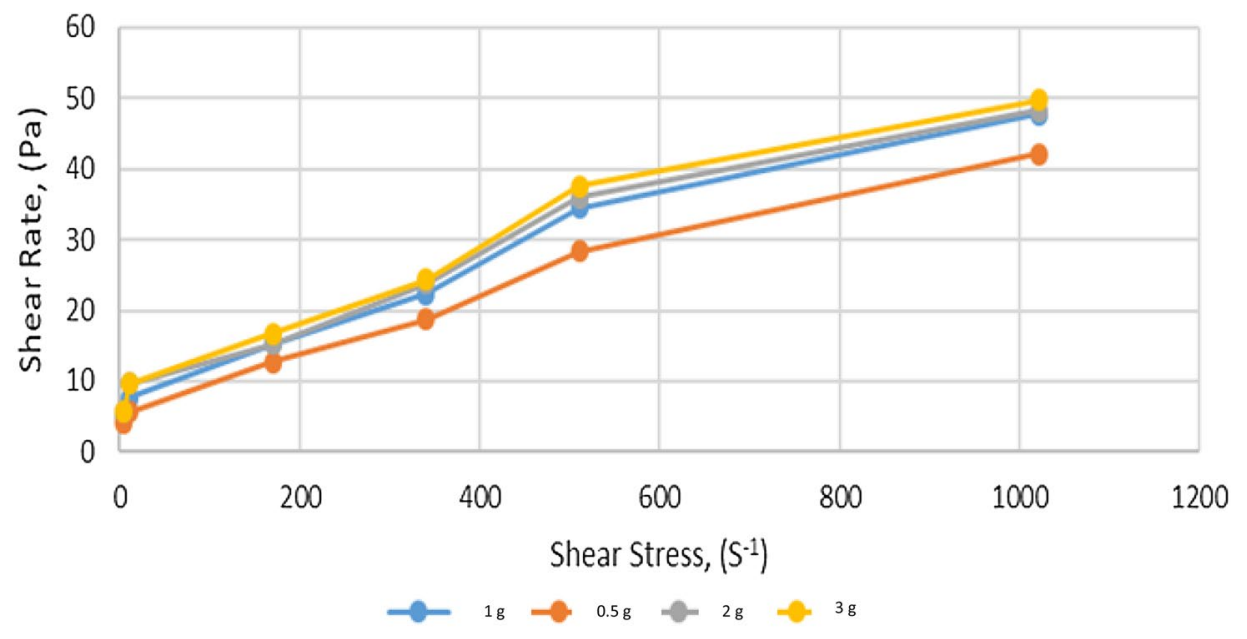

(a) Shear Stress against Shear Rate at different concentrations of MWCNT for OBM

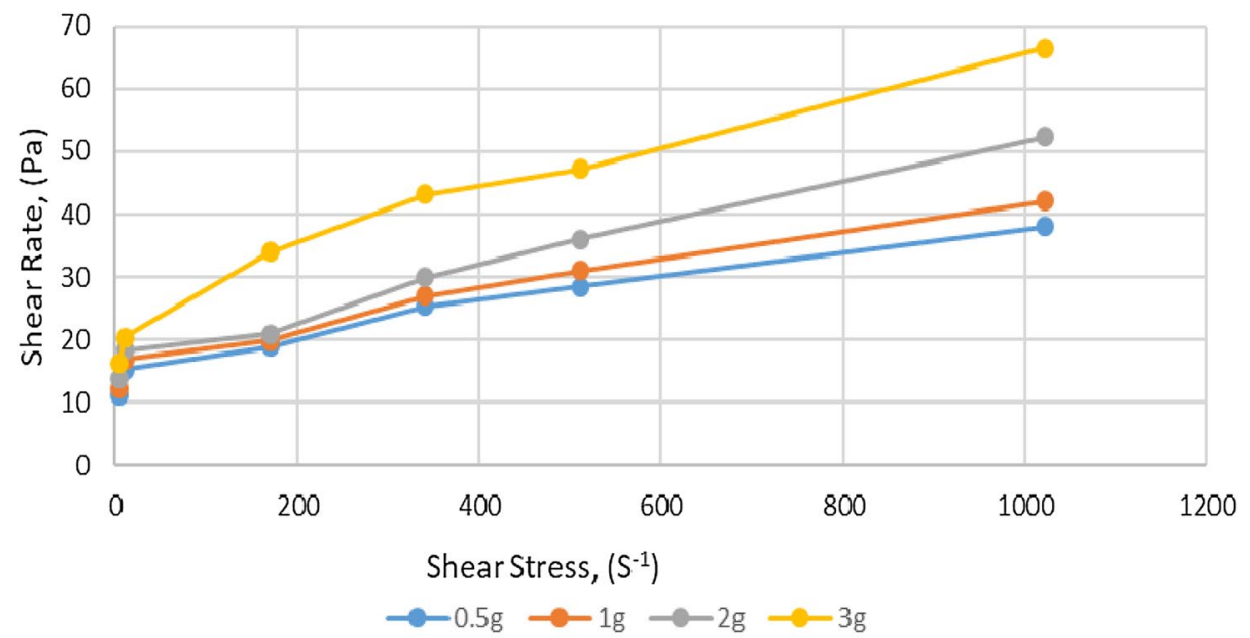

(b) Shear Stress against Shear Rate at different concentrations of MWCNT for WBM 
system. The experimental result shows an initial increase in the plastic viscosity of the oil- and water-based mud systems before obtaining an optimum value of the MWCNT concentration for both the WBM and OBM (Fig. 2). The slight increase in PV with increase in concentration of MWCNT can be attributed to the low solubility in both water and oil, which makes it remain in the fluid as dispersed particles. Figure 2 identifies that the optimum concentrations of MWCNT for effective cutting carrying capacity are $2 \mathrm{ppb}$ and $2.5 \mathrm{ppb}$ for water-based mud (WBM) and oil-based mud, respectively. MWCNTs possess enhanced physiochemical properties that can be attributed to their tiny size along with their extremely high surface-to-volume ratio. Figure $2 \mathrm{com}$ pares the plastic viscosities of the oil-based mud and waterbased mud systems at different concentrations of MWCNT. It can be seen that both mud systems exhibited the same behavior as the concentration of MWCNT is increased.
Decreasing the size of the solids at a constant volume also increases the plastic viscosity which confirms the effect of MWCNT size and concentration on the plastic viscosity.

\section{Yield point}

The yield point (YP) of a drilling fluid by definition is the mud's initial resistance to flow, primarily caused by reactions of an electrochemical nature taking place between the particles of the solids present in the mud (Abduo et al. 2016). An optimum concentration of $2 \mathrm{ppb}$ is observed for the WBM, after which the yield point begins to decline. However, for the OBM, it is observed that increases in the concentration of MWCNT in the mud yield a corresponding slight increase in the values of the yield point with $2.5 \mathrm{ppb}$ as a clear optimal value as seen in Fig. 3. Srungavarapu et al. (2018) highlighted the high yield point to plastic viscosity
Fig. 2 Plastic viscosities at different concentrations of MWCNT for WBM and OBM

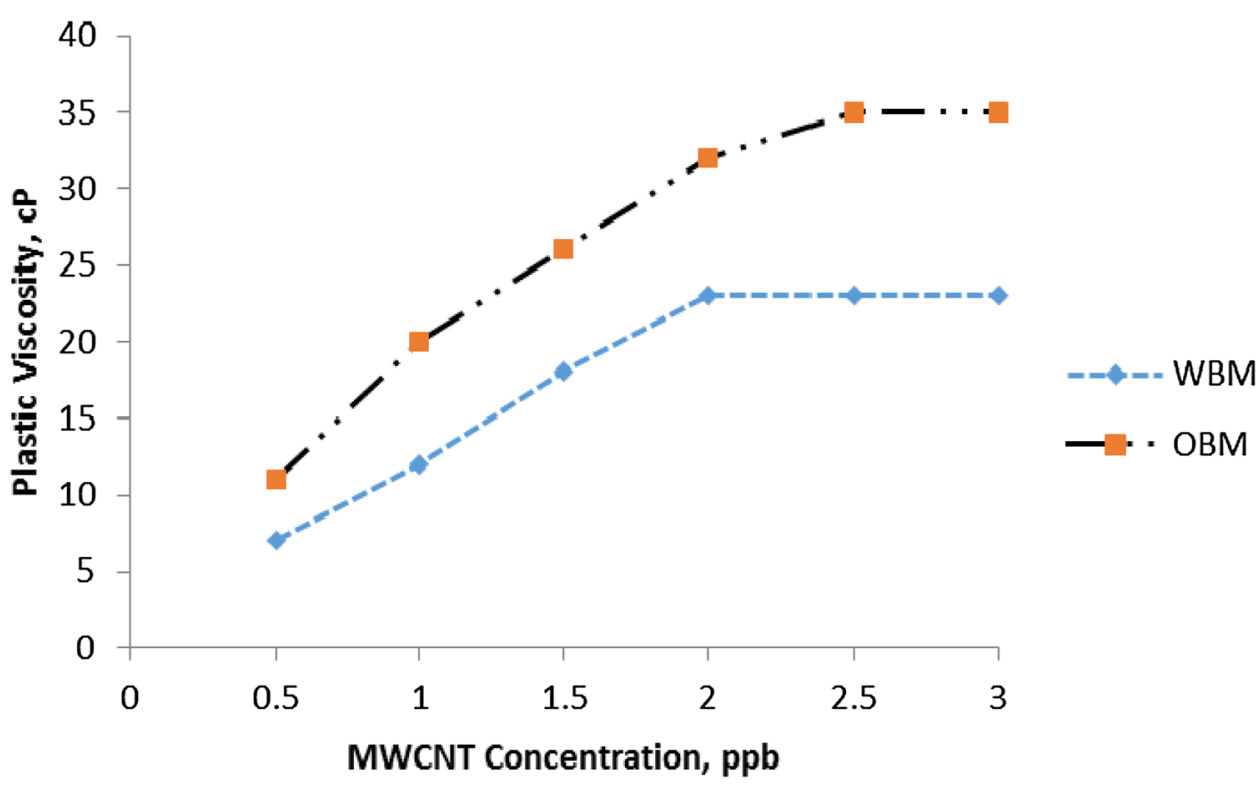

Fig. 3 Yield point at different concentrations of MWCNT for WBM and OBM

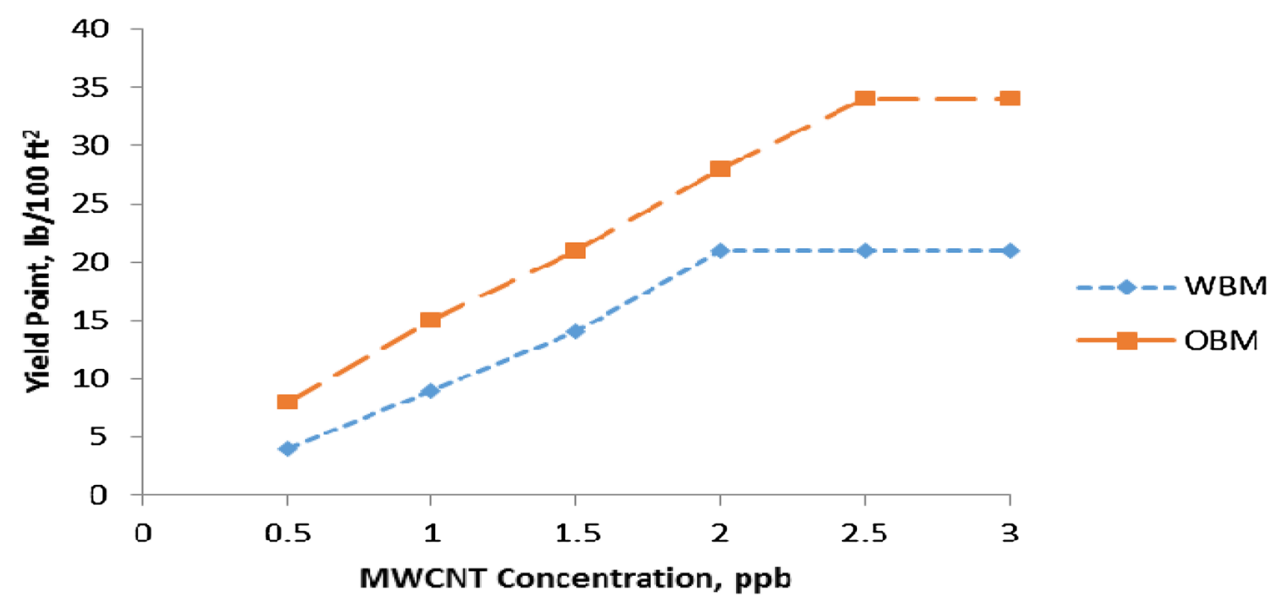

MWCNT Concentration, ppb 
Fig. 4 Gel strength at different concentrations of MWCNT for OBM
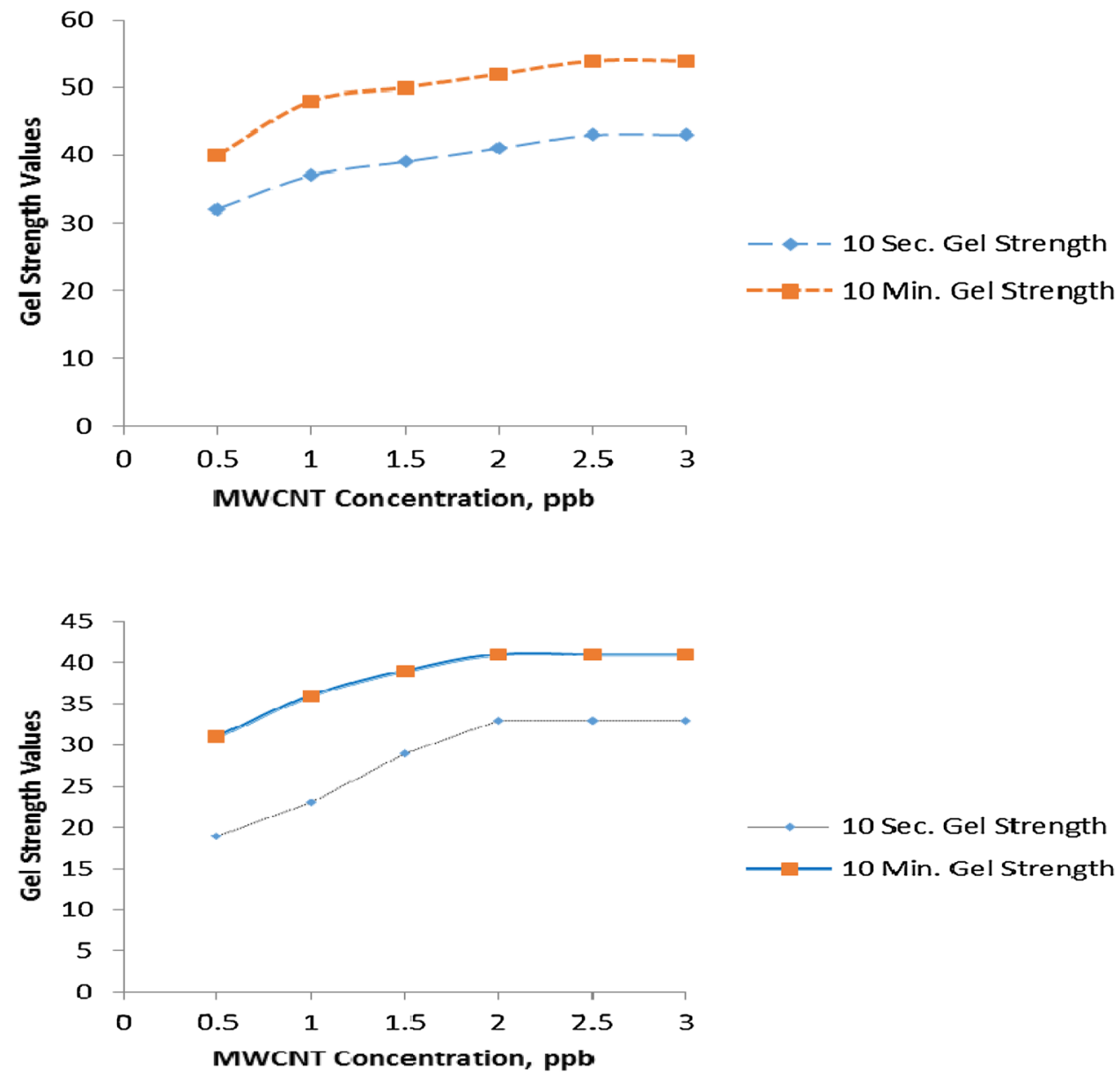

Fig. 5 Gel strength at different concentrations of MWCNT for WBM ratio value as an indication to the shear-thinning behavior of the mud systems, which is highly desirable for the drilling mud to optimally suspend the drilling cuttings during drilling operations.

\section{Gel strength}

The gel strength of a mud helps it hold cuttings during drilling operations and when drilling is suspended (Baker Hughes 2006). The measure of the attractive forces present in a drilling mud system at static condition is known as gel strength. The gel strength results from the experiment for $10 \mathrm{~s}$ and $10 \mathrm{~min}$ are shown in Figs. 4 and 5. From the figures, it is observed that increasing the concentration of the MWCNT yields corresponding slight increases in the 10-s and 10-min gel strength for the WBM and OBM. However, there exists a remarkable difference between their gel development patterns. For instance, the WBM shows progressive gelling tendencies that were later stabilized as seen in the $10 \mathrm{~s}$ and 10 min' gel values while the OBM exhibits fragile gelling tendencies for the $10 \mathrm{~s}$ and $10 \mathrm{~min}$ ' gel strength evaluation. Progressive high gel strength is not ideal as it

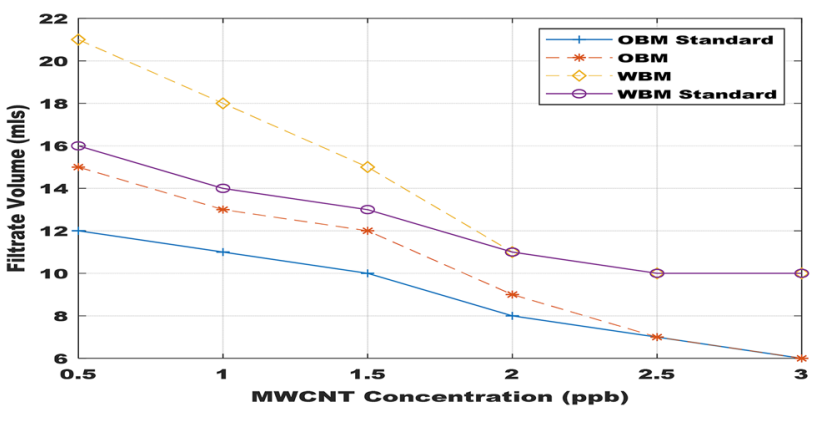

Fig. 6 Comparison of fluid loss at different concentrations of standard and MWCNT for OBM and WBM

can cause instability conditions around the wellbore during drilling operations. Also, drilling mud system with low gel strength cannot suspend drilling cuttings and weighting materials during drilling. Generally, a flat gel condition is observed. Flat gel is a situation in which 10-s and 10-min gel strengths for a drilling mud have close values. It indicates that the mud systems will remain pumpable with time if left 
static in the hole when drilling operation is stopped for any reason.

\section{Effect of MWCNT on the mud systems filtration loss}

\section{Effect of MWCNT on filtrate volumes}

Figure 6 shows the volume of mud filtrate measured after 30 min of static filtration test in the laboratory. Standard mud samples were formulated using another macroscopic particle as filtration loss additive for the OBM and WBM. For the OBM, at an initial concentration of $0.5 \mathrm{ppb}$ of MWCNT, a filtrate volume of $15 \mathrm{mls}$ was recorded, while the standard used as control recorded $12 \mathrm{mls}$. The trend in Fig. 6 shows that as the concentration of the MWCNT was increased, there was a reduction in the filtrate volume margin. The 3 ppb concentration of MWCNT gave 6 mls (Fig. 6). The increase in concentration of the MWCNT resulted in a $50 \%$ reduction in fluid loss from the initial value while an increase in the concentration of the standard reduced fluid loss by $54 \%$. However, for the WBM, equivalent amounts of MWCNT recorded less fluid loss than the standard. MWCNT concentration of 3 ppb recorded a $51 \%$ decrease in filtration volume generated and a $45 \%$ decrease in fluid loss for the standard case. The lower volumes of filter loss in the case of the WBM may be attributed to the optimum dispersion of the MWCNT.

\section{Effect of MWCNT on cake thickness}

Under dynamic conditions, filter cake thickness depends on rate of deposition versus erosion caused by fluid circulation and mechanical abrasion by the rotating drill string. In the laboratory test, filter cake is formed under static conditions using filter press equipment with no erosion (see Fig. 9 under "Appendix" for thickness measurement picture). A moderately hard, firm, 2.0-mm-thick cake was reported for all concentrations of standard and MWCNT for the WBM (Table 4), while a moderately hard, firm, 1-mm-thick cake was observed for the OBM (Table 5). The seeming reluctance of the cake thickness to change despite variations in the concentration of the MWCNT additive suggests that concentration of the MWCNT has little or no effect on cake thickness. On the other hand, the thin mud cake $(1 \mathrm{~mm})$ recorded for the OBM shows that it would not likely pose any challenge to the progress of drilling when used in the field. Figure 7 shows the morphology of the filter cake formed during the filtration test, and it is clear that the characteristics of the filter cake at optimum values of $2 \mathrm{ppb}$ and $2.5 \mathrm{ppb}$ for WBM and OBM systems gave an ideal semi-impermeable mud cake that prevents filtrate from slipping into the formation. Thus, it has the ability to reduce formation damage caused by filtrate during drilling operation.

To understand the morphological behavior of the filter cake formed during the filtration test, Scanning electron microscope (SEM) was utilized at high resolution. Figure 7 shows the SEM images of the filter cake surface formed during the filtration test. The reduction in filtrate volume for the mud systems was as a result of uniform, closely parked surface and significant reduction in pore space between the mud solutes (colloidal particles) under pressure. The filter cake with the MWCNT had a fine surface morphology and less porous structure as a benefit of using a nanoparticle.

Table 4 Filter cake characterization for WBM

\begin{tabular}{lll}
\hline Quantity $(\mathrm{g})$ & Standard filter cake characteristics & MWCNT filter cake characteristics \\
\hline 0.5 & Cake thickness $2.0 \mathrm{~mm}$ (moderately hard, firm) & Cake thickness 2.0 mm (moderately hard, firm) \\
1 & Cake thickness $2.0 \mathrm{~mm}$ (moderately hard, firm) & Cake thickness 2.0 mm (moderately hard, firm) \\
1.5 & Cake thickness $2.0 \mathrm{~mm}$ (moderately hard, firm) & Cake thickness 2.0 mm (moderately hard, firm) \\
2.0 & Cake thickness $2.0 \mathrm{~mm}$ (moderately hard, firm) & Cake thickness 2.0 mm (moderately hard, firm) \\
2.5 & Cake thickness $2.0 \mathrm{~mm}$ (moderately hard, firm) & Cake thickness $2.0 \mathrm{~mm}$ (moderately hard, firm) \\
3.0 & Cake thickness $2.0 \mathrm{~mm}$ (moderately hard, firm) & Cake thickness 2.0 mm (moderately hard, firm) \\
\hline
\end{tabular}

Table 5 Filter cake characterization for OBM

\begin{tabular}{lll}
\hline Quantity $(\mathrm{g})$ & Standard filter cake characteristics & MWCNT filter cake characteristics \\
\hline 0.5 & Cake thickness $1 \mathrm{~mm}$ (moderately hard, firm) & Cake thickness $1 \mathrm{~mm}$ (moderately hard, firm) \\
1.0 & Cake thickness $1 \mathrm{~mm}$ (moderately hard, firm) & Cake thickness $1 \mathrm{~mm}$ (moderately hard, firm) \\
1.5 & Cake thickness $1 \mathrm{~mm}$ (moderately hard, firm) & Cake thickness $1 \mathrm{~mm}$ (moderately hard, firm) \\
2.0 & Cake thickness $1 \mathrm{~mm}$ (moderately hard, firm) & Cake thickness $1 \mathrm{~mm}$ (moderately hard, firm) \\
2.5 & Cake thickness $1 \mathrm{~mm}$ (moderately hard, firm) & Cake thickness $1 \mathrm{~mm}$ (moderately hard, firm) \\
3.0 & Cake thickness $1 \mathrm{~mm}$ (moderately hard, firm) & Cake thickness $1 \mathrm{~mm}$ (moderately hard, firm) \\
\hline
\end{tabular}



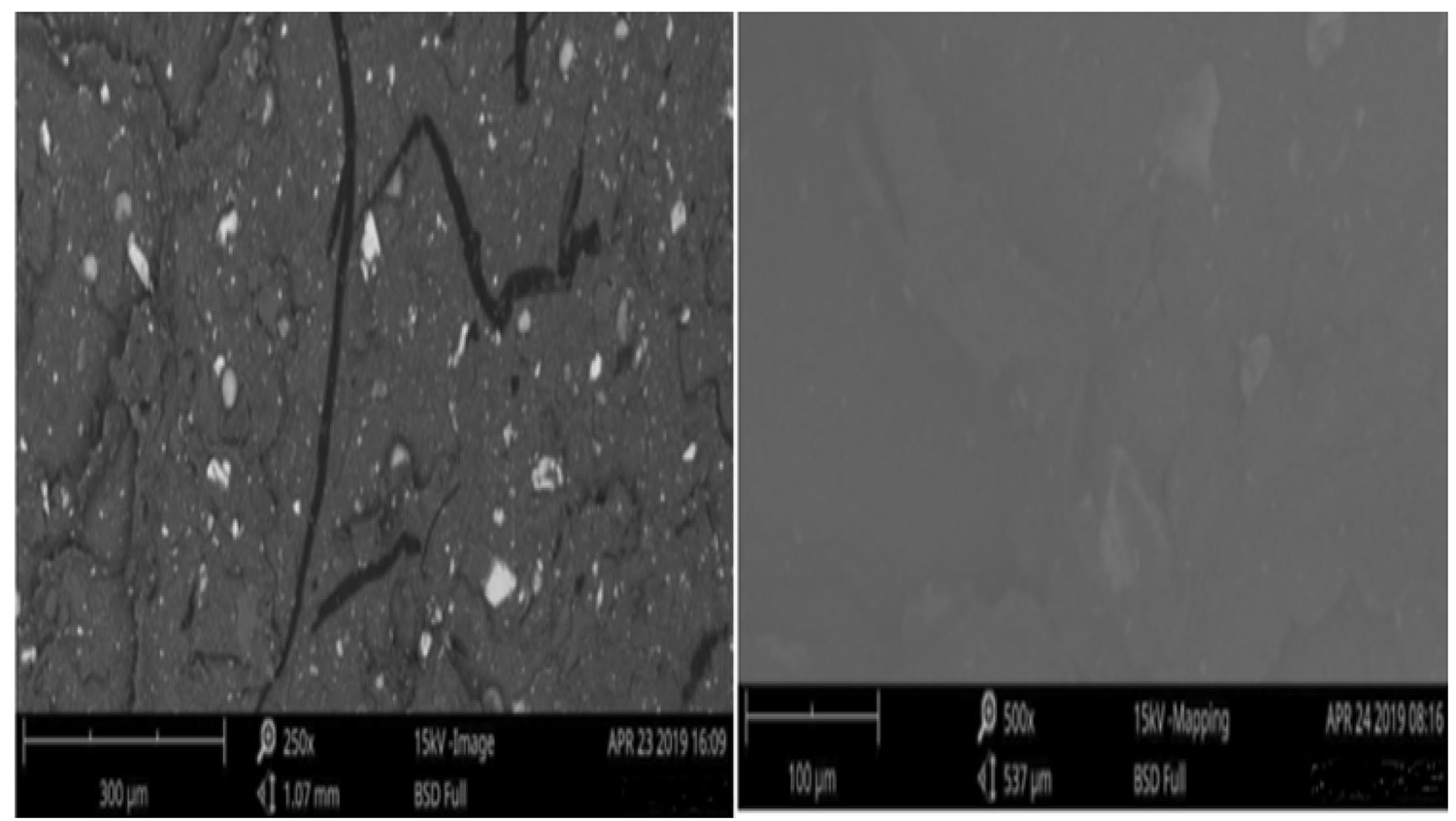

Fig. 7 SEM analysis of the filter cake morphology

Table 6 Cake permeability for WBM and OBM formulated with MWCNT

\begin{tabular}{lll}
\hline $\begin{array}{l}\text { Concentration of } \\
\text { MWCNT }(\mathrm{ppb})\end{array}$ & \multicolumn{2}{l}{ Cake permeability $(\mathrm{mD})$} \\
\cline { 2 - 3 } & OBM $\left(\times 10^{-3}\right)$ & $\mathrm{WBM}\left(\times 10^{-3}\right)$ \\
\hline 0.5 & 1.969 & 5.069 \\
1 & 1.656 & 4.554 \\
1.5 & 1.41 & 3.6909 \\
2 & 1.119 & 3.007 \\
2.5 & 1.029 & 2.578 \\
3 & 0.716 & 2.105 \\
\hline
\end{tabular}

It showed chain-like structures that is believed to have increased the surface area of the filter cake and enhanced its ability to interact more efficiently. Characterizing the formed filter cake is critical in understanding the wellbore cleaning during well completion operations.

In order to ascertain the permeability of the mud cake formed by both muds, the relation developed by Lomba (2010) which is shown in Eq. 1.1 is applied:

$K=Q_{\mathrm{f}} \times \varepsilon \times \mu \times 8.95 \times 10^{-5}$

where $K$ is the cake permeability in millidarcy, $Q_{\mathrm{f}}$ is the fluid loss in cubic centimeters, $\varepsilon$ is the thickness of the mud cake measured in millimeters and $\mu$ is the viscosity of the liquid phase of the mud in centipoise. Using the relation by Lomba (2010), and the viscosity of diesel as $2.4 \mathrm{cP}$ at $65^{\circ} \mathrm{F}$ (Geotech, online), we obtain the permeability of the cakes at different MWCNT concentrations as shown in Table 6
From Table 6, the values of cake permeability for the WBM are seen to be higher than those of the OBM. This establishes the reason the filter loss volumes in the case of the WBM were higher than those recorded for the OBM.

Monitoring and controlling the rheological properties of the drilling mud system is part of the efforts for successful wellbore drilling. Outside rheology, which is a key property that is often optimized for stable and effective mud system, filtration is another property that drillers pay attention to, in order to promote safer and less expensive drilling operation. Invasion of drilling mud filtrate into the newly exposed formations is one of the most common causes of formation damage, leading to costly stimulation treatments during wellbore completion and even reduction in production due to reservoir impairment. This problem has been known for decades as a major contributor to the abnormal decline in productivity or injectivity in most reservoirs. The most important criteria for drilling mud systems used for drilling operations are to have a sufficient viscosity, yield strength, cutting carrying capacity and minimal filtration properties in order to have good wellbore stability, reduced interaction between the formation pore fluids and the drilling mud system. The experimental results show that the addition of MWCNT to the oil- and water-based mud systems reduces the filtrate volume, and the study also identified an optimum MWCNT concentration for achieving the desired result for the formulation used. The results obtained indicated that MWCNT as filtrate loss control agent could form an ideal filter cake. Rule of thumb has shown that an ideal filter cake is thin, tough, fast to form, flexible and 
with a very low permeability as seen with the mud systems formulated with the optimum MWCNT concentration. The thin filter cake is preferred in the drilling operation to avoid wellbore instability problems and reduce the volume of acid required to remove the filter cake during wellbore cleaning operation. Therefore, it can be concluded that MWCNT can play an important role in preventing drilling-associated borehole problems associated with drilling mud systems, since invasion of mud filtrate while drilling is considered one of the most common sources of formation damage.

\section{Conclusions}

This study investigated the performance of high concentrations of multiwalled carbon nanotubes as drilling mud systems filtrate loss control additives. From the results obtained, the following conclusions are drawn:

1. That multiwalled carbon nanotubes can serve as filter loss control agents in both OBM and WBM systems.

2. The optimal concentration for using multiwalled carbon nanotubes to effectively reduce filtrate penetration is $2 \mathrm{ppb}$ and $2.5 \mathrm{ppb}$ for WBM and OBM, respectively.

3. Since multiwalled carbon nanotubes exhibited thin mud cake values when formulated with oil-based muds coupled with their thermally stability at high temperatures, its usefulness as fluid loss control material has been well established.

Open Access This article is distributed under the terms of the Creative Commons Attribution 4.0 International License (http://creativeco mmons.org/licenses/by/4.0/), which permits unrestricted use, distribution, and reproduction in any medium, provided you give appropriate credit to the original author(s) and the source, provide a link to the Creative Commons license, and indicate if changes were made.

\section{Appendix}

See Figs. 8 and 9.

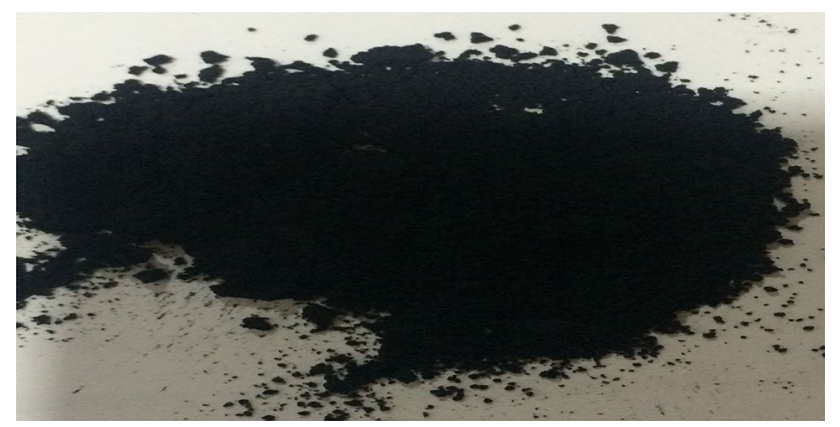

Fig. 8 MWCNT picture

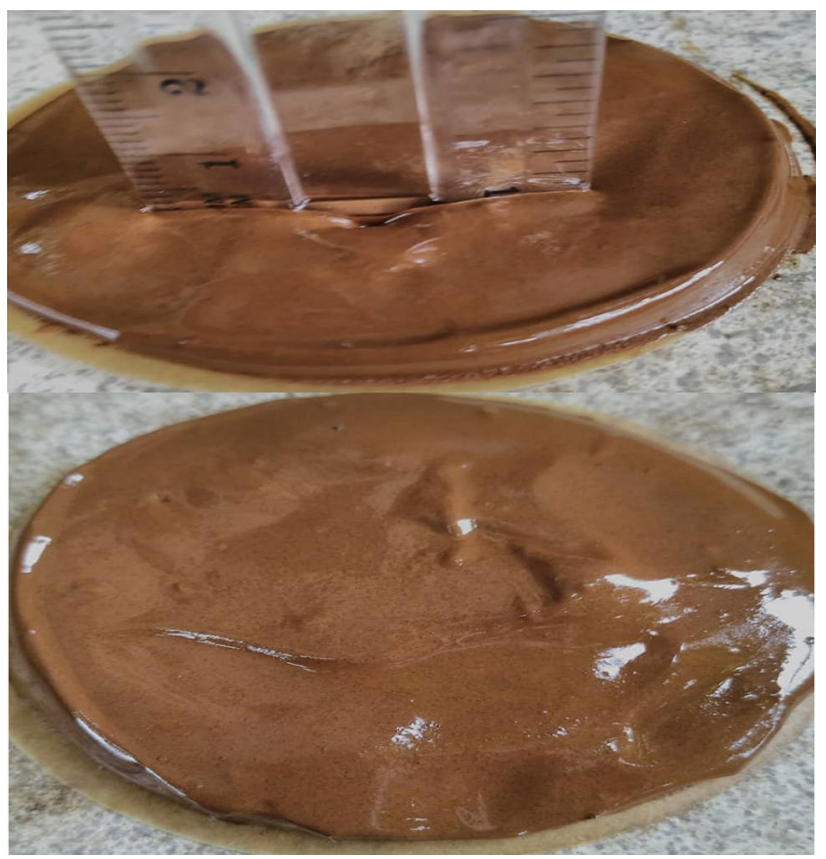

Fig. 9 Filter cake from the filtration test and its measurement

\section{References}

Abduo MI, Dahab AS, Hesham A, Abdulaziz MA, Elhossieny MS (2016) Comparative study of using water-based mud containing multiwall carbon nanotubes versus oil-based mud in HPHT fields. Egypt J Pet 25:459-464

Aftab A, Ismail AR, Khokhar S, Ibupoto ZH (2016) Novel zinc oxide nanoparticles deposited acrylamide composite used for enhancing the performance of water-based drilling fluids at elevated temperature conditions. J Pet Sci Eng 146:1142-1157

Agwu OE, Akpabio JU (2018) Using agro-waste materials as possible control agents for filter loss in drilling muds: a review. J Pet Sci Eng 163:185-198

Ahmad HM, Kamal MS, Murtaza M, Al-Harthi MA (2017) Improving the drilling fluid properties using nanoparticles and water-soluble polymers. In: SPE annual technical symposium and exhibition, Kingdom of Saudi Arabia

Allahvirdizadeh P, Kuru E, Parlaktuna M (2016) Experimental investigation of solids transport in horizontal concentric annuli using water and drag reducing polymer-based fluids. J Nat Gas Sci Eng 35:1070-1078

Azouz KB, Bekkour K, Dupuis D (2016) Influence of the temperature on the rheological properties of bentonite suspensions in aqueous polymer solutions. Appl Clay Sci 123:92-98

Baker Hughes (2006) Drilling fluids engineering reference manual, Chap 1, pp 1-33

Binqiang X, Li T, Yan Z, Chen L (2018) Rheological properties of bentonite-free water-based drilling fluids with novel polymer viscosifier. J Pet Sci Eng 164:302-310

Bourgoyne AT Jr, Millheim KK, Chenevert ME, Young FS Jr (1991) Applied drilling engineering. SPE textbook series 2, 3rd edn. Society of Petroleum Engineers, Richardson

Dias FTG, Souza RR, Lucas EF (2015) Influence of modified starches composition on their performance as fluid loss additives in invertemulsion drilling fluids. Fuel 140:711-716 
Dmitry K, Ceriotti G, Wilson KC, Lomeda JR, Scorsone JT, Patel DA, Friedheim JE, Tour JM (2011) Graphene oxide as a highperformance fluid-loss-control additive in water-based drilling fluids. ACS Appl Mater Interfaces 4:222-227

Drilling Formulas (2016) API and HTHP fluid loss. http://www.drill ingformulas.com/api-and-hthp-fluid-loss/. Accessed 24 June 2018

Ekeinde EB, Okoro EE, Dosunmu A, Iyuke S (2018) Optimizing aqueous drilling mud system viscosity with green additives. J Pet Explor Prod Technol. https://doi.org/10.1007/s13202-018-0481-0

Geotech (online) Average viscosities of miscellaneous liquids. http:// www.geotechenv.com/Reference_Pages/average_viscosities_liqui ds.pdf. Accessed 15 July 2018

Hamed SB, Belhadri M (2009) Rheological properties of biopolymers drilling fluids. J Petrol Sci Eng 67:84-90

Igwe I, Kinate BB (2015) The use of periwinkle shell ash as control agents for filter loss in water-based muds. Int $\mathrm{J}$ Eng Res 3(6):375-381

Ismail AR, Seong TC, Buang NA, Wan Rosli WS (2014) Improve performance of water based drilling fluids using nanoparticles. In: Proceedings of 5th Sriwijaya international seminar on energy and environmental science and Technology, Palembang, Indonesia, September 10-11, 2014

Ismail AR, Aftab A, Ibupoto ZH, Zolkifile N (2016) The novel approach for the enhancement of rheological properties of waterbased drilling fluids using multi-walled carbon nanotubes, nanosilica and glass beads. J Pet Sci Eng 139:264-275

Lomba R (2010) Fundamentos de filtração e controle das propriedades de filtração, Report (in Portuguese)

M-I Swaco Drilling Fluids Engineering Manual (2006)

Mehra NK, Mishra V, Jain NK (2014) A review of ligand tethered surface engineered carbo nanotubes. Biomaterials 35(4):1267-1283

Mostafa S, Babak FA, Khalil S (2016) Thermal and rheological properties improvement of oil-based drilling fluids using multi-walled carbon nanotubes. J Pet Sci Technol 6(2):37-44

Okoro EE, Dosunmu A, Oriji B, Iyuke S (2015) Impact of reversible invert emulsion drilling fluid rheology on productivity. SPE178308-MS. In: SPE Nigerian annual technical conference and exhibition, Lagos

Okoro EE, Igwilo KC, Ifeka K, Okafor IS, Sangotade I (2018) Cellulosic Cyperus esculentus L. as a filtrate loss modifier in field applicable aqueous and non-aqueous drilling fluids. J Pet Explor Prod Technol 9:1331-1337. https://doi.org/10.1007/s1320 2-018-0580-y
Oscar C, Geir H, Maen H, Runar N, Mortadha A (2014) SPE118116-MS. In: SPE international symposium and exhibition on formation damage control, 26-28 February, Lafayette, Louisiana, USA

Shadfar D, Ahmad SA, Khalil S, Sajad M (2016) An experimental investigation on the use of multi-walled carbon nanotubes to improve the performance of an oil field applicable water-based mud. Int J Eng Res Gen Sci 4(4):277-283

Sharma MM, Chenevert ME, Guo Q, Ji L, Friedheim J, Zhang R (2012) A new family of nanoparticle based drilling fluids. In: Proceedings of the SPE annual technical conference and exhibition, San Antonio, TX, USA

Srungavarapu M, Patidar KK, Pathak AK, Mandal A (2018) Performance studies of water-based drilling fluid for drilling through hydrate bearing sediments. Appl Clay Sci 152:211-220

Vipulanandan C, Mohammed A (2015) Effect of nanoclay on the electrical resistivity and rheological properties of smart and sensing bentonite drilling muds. J Petrol Sci Eng 130:86-95

Vryzas Z, Kelessidis VC (2017) Nano-based drilling fluids: a review. Energies 10(4):540

Wang X, Li Q, Xie J, Zhong JW, Yan L, Kaili J, Shoushan F (2009) Fabrication of ultralong and electrically uniform single walled carbon nano-tubes on clean substrate. Nano Lett 9(9):3137-3141

Warren BK, Smith TR, Ravi KM (1993) Static and dynamic fluidloss characteristics of drilling fluids in a full-scale wellbore. SPE 26069. In: SPE western regional meeting, Anchorage, Alaska, 26-28 May

Wepasnick KA, Smith BA, Schrote KE, Wilson HK, Diegelmann SR, Howard Fairbrother D (2011) Surface and structural characterization of multi-walled carbon nanotubes following different oxidative treatments. Carbon 49(2011):24-36

Xuan Y, Jiang G, Li J (2014) Nanographite oxide as ultrastrong fluidloss-control additive in water-based drilling fluids. Dispers Sci Technol 35:1386-1392

Publisher's Note Springer Nature remains neutral with regard to jurisdictional claims in published maps and institutional affiliations. 